\title{
Experimental and Numerical Analysis of Hull Girder Vibrations and Bow Impact of a Large Ship Sailing in Waves
}

\author{
Jialong Jiao, Huilong Ren, and Christiaan Adika Adenya \\ College of Shipbuilding Engineering, Harbin Engineering University, Harbin 150001, China \\ Correspondence should be addressed to Huilong Ren; renhuilong@263.net
}

Received 30 April 2015; Accepted 15 July 2015

Academic Editor: Hassan Haddadpour

Copyright (C) 2015 Jialong Jiao et al. This is an open access article distributed under the Creative Commons Attribution License, which permits unrestricted use, distribution, and reproduction in any medium, provided the original work is properly cited.

\begin{abstract}
It is of great importance to evaluate the hull structural vibrations response of large ships in extreme seas. Studies of hydroelastic response of an ultra large ship have been conducted with comparative verification between experimental and numerical methods in order to estimate the wave loads response considering hull vibration and water impact. A segmented self-propelling model with steel backbone system was elaborately designed and the experiments were performed in a tank. Time domain numerical simulations of the ship were carried out by using three-dimensional nonlinear hydroelasticity theory. The results from the computational analyses have been correlated with those from model tests.
\end{abstract}

\section{Introduction}

The 21st century is a century of the ocean. Many new industries such as ocean oil and gas, ocean chemical industry, and deep-sea mining will be formed. The demand for ultra larger ships has increased dramatically in the last few years with the marine industry requirement for more energy efficient ships and as world trade continues to grow. Large ships are relatively more flexible and their structural natural frequencies can fall into the range of the encounter wave frequencies in an ordinary sea state [1]. Therefore, hull girder vibration and the response due to wave impact must be taken into account for the design and operation of large ships.

The international marine community renewed the interest in studying the feasibility of using ultra large ships. In order to ensure their safety at sea, their structural responses in the sea are of particular importance $[2,3]$. The classical approach to determine ship motions and wave loads is based on the assumption that the ship hull acts as a rigid body. However, this approach is not reliable enough for ultra large ships due to mutual influence of the wave loads and structure response. Therefore, a reliable solution requires analysis of wave loads and ship vibration as a coupled hydroelastic problem $[4,5]$.
It is especially important to consider impulsive loads such as ship slamming that causes whipping. Whipping is a transient vibration induced in ship girder by slamming. During whipping rapid flexing of the hull girder occurs. The behavior of slamming pressure acting on hull surfaces is known to become significant as the ship's sailing speed increases. Many articles about the wave impact or slamming pressure have been published $[6,7]$. Hydrodynamic impact of a ship can be mainly classified into bow impact and flare impact [8]. Flare slamming occurs with the bow flare of a vessel hitting an oncoming wave. Occasionally stern counter slamming could also lead to high whipping responses. Slamming event often causes an extremely large load with high transient local pressure on the bodies and subsequently the whipping forces to the entire hull structures. As a result, it can lead to substantial damage in the structures of ship hulls and marine facilities.

For the investigation of wave loads considering hull girder vibration and bow slamming of a large ship, a segmented self-propelling ship model with a steel backbone system $[9$, 10] was adopted first. Then, experimental results of head waves in different sea states and at different sailing speeds were described and analyzed. Lastly, three-dimensional time domain nonlinear hydroelasticity theory $[11,12]$ was adopted 
TABLE 1: Main dimensions.

\begin{tabular}{lcc}
\hline Principal dimension & Prototype & Model \\
\hline Scale & $1 / 1$ & $1 / 50$ \\
Overall length [m] & 313 & 6.26 \\
Waterline length [m] & 292 & 5.84 \\
Moulded breadth [m] & 39.5 & 0.79 \\
Depth [m] & 25.5 & 0.51 \\
Draft [m] & 10 & 0.20 \\
Displacement [T] & 71875 & 0.575 \\
VCG from BL [m] & 16 & 0.32 \\
LCG from AP [m] & 145 & 2.81 \\
$K_{z z}[\mathrm{~m}]$ & 13.5 & 0.27 \\
$K_{y y}[\mathrm{~m}]$ & 73 & 1.46 \\
\hline
\end{tabular}

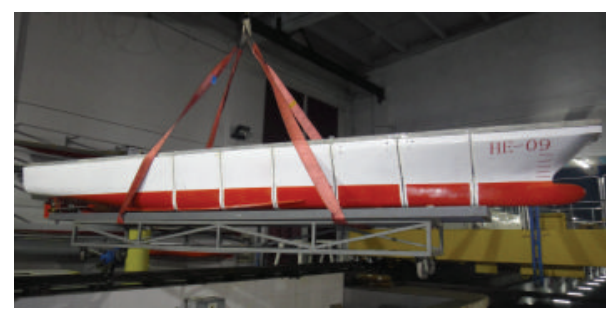

FIgURE 1: Model hull.

to simulate the wave loads. And the results of numerical simulation were compared with the test results.

\section{Model Design}

2.1. Model Setup. To investigate the hydroelastic response of a large ship in waves, a fiberglass reinforced plastic (FRP) segmented hull with a steel backbone at its neutral axis was made with a scale ratio of $1: 50$. The model parameters are shown in Table 1. In the table, VCG denotes vertical centre of gravity, LCG denotes longitudinal centre of gravity, $\mathrm{BL}$ denotes baseline, AP denotes after perpendicular, $K_{z z}$ denotes transverse radius of gyration, and $K_{y y}$ denotes longitudinal radius of gyration.

The model has 20 divisions and was divided into seven segments by using the $2 \mathrm{nd}, 4 \mathrm{th}, 6 \mathrm{th}, 8 \mathrm{th}, 10 \mathrm{th}$, and 12 th divisions. The segmented hulls were connected by the backbone model. Segmented hulls are used to transfer the hydrodynamic force experienced by the hulls to the backbone. The gaps between each two segmented hulls are provided to prevent mutual touching during the slight deformation of the backbone model in waves. Wave loads at $2 \mathrm{nd}, 4 \mathrm{th}, 6 \mathrm{th}$, 8 th, 10th, and 12th divisions, that is, disconnected sections, were measured by four rosette strain gauges placed on the backbone. The monolithic large space at the stern, which has the 13th to 20th divisions, is used for installing the propulsion system. The model's photo is shown in Figure 1 and the backbone system is shown in Figure 2.

2.2. Measurement of Bow Impact. The behaviors of bow slamming pressure on the hull surface of alternately wet and

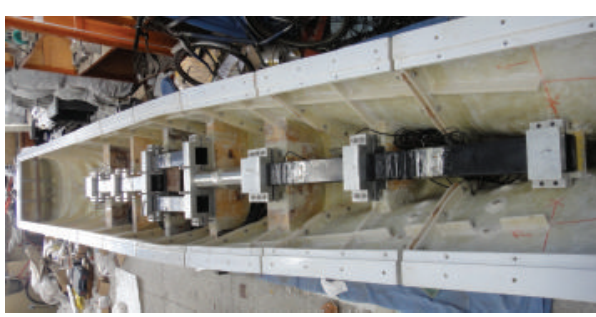

FIGURE 2: Backbone system.

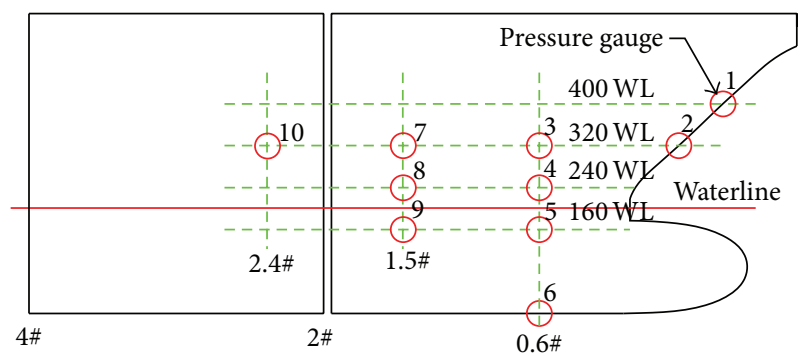

FIgURE 3: Pressure gauges arrangement.

dry areas near the waterline and on the bow zone were studied in particular. Several pressure gauges were disposed at bow of the hull, as seen in Figure 3, to measure the impact pressure from waves. The sensors have a range of $100 \mathrm{kPa}$ and an accuracy of $10 \mathrm{~Pa}$. The sampling frequency of pressure gauges was set as $200 \mathrm{~Hz}$ during the tests.

2.3. Matching of Modes Characteristics. The vibration characteristics of the hull must be taken into account while designing the model. In order to design the backbone model, vibration characteristic parameters of the prototype ship should be obtained first. Distributions of mass and vertical moment of inertia of prototype ship are shown in Figure 4. With parameters such as the distributions of mass, vertical moment of inertia, and shear area, then the vertical vibration dry modes and natural frequencies of the ship hull girder were calculated by transfer matrix method which idealizes the ship structure as a Timoshenko beam. Figure 5 shows the vertical displacement mode shapes along the ship length of first three orders of the prototype ship calculated by transfer matrix method. Then natural frequency of the model ship in dry condition could be obtained by use of the similitude rule. The configuration and dimension of the backbone model was designed to match the stiffness distribution and first-order natural frequency of vertical bending in dry condition of the prototype ship. Tubular structure steel backbones with variable cross section were designed for this model. The inner wall parameters, that is, width and height of the rectangular tubular structure backbones, remained unchanged, whereas the thicknesses at different sections was changed so as to meet the structure stiffness requirement.

In order to check the longitudinal strength and natural frequencies of the segmented model, the impact hammer tests were performed in both dry and wet conditions. Figure 6 shows the time history of the vertical bending response 


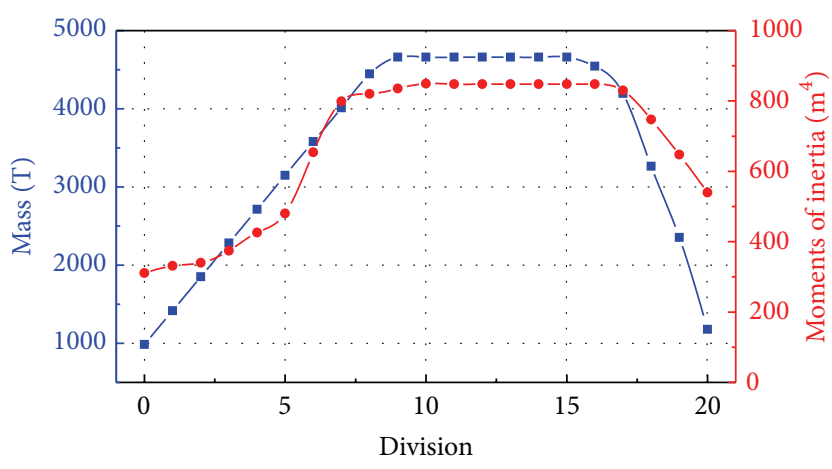

Figure 4: Distributions of mass and vertical moment of inertia.

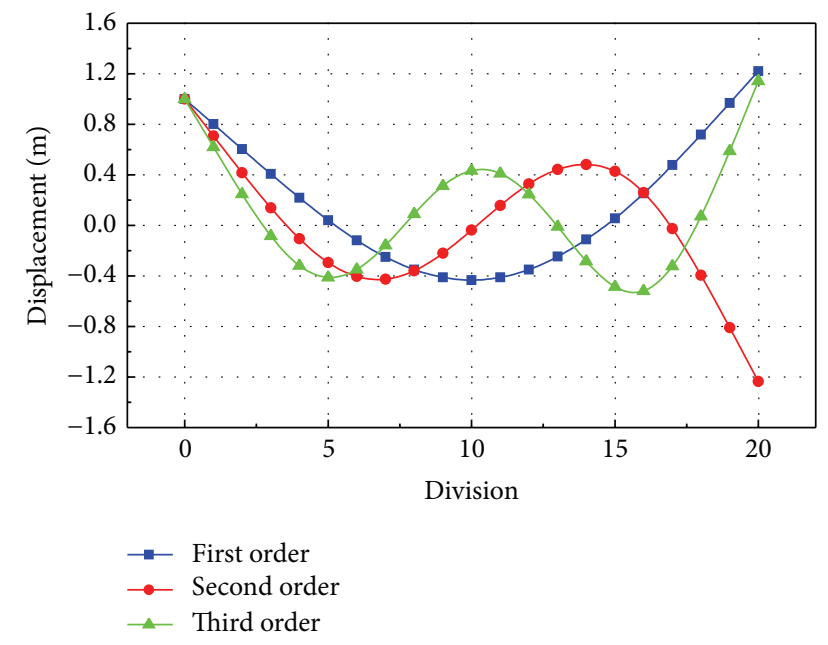

FIGURE 5: Distributions of displacement modes.

TABLE 2: Wet natural frequencies of model ship.

\begin{tabular}{lccc}
\hline Mode & $\begin{array}{c}\text { Test result } \\
(\mathrm{Hz})\end{array}$ & $\begin{array}{c}\text { Simulate result } \\
(\mathrm{Hz})\end{array}$ & $\begin{array}{c}\text { Error } \\
\%\end{array}$ \\
\hline First order & 4.652 & 4.731 & 1.7 \\
Second order & 12.766 & 14.038 & 9.1 \\
Third order & 17.066 & 24.065 & 29.1 \\
\hline
\end{tabular}

recorded by strain gauges placed on the backbone during the hammer test in wet condition. The measured two-node natural frequency of the model was about $4.652 \mathrm{~Hz}$ by fast Fourier transform (FFT). Since the ship moves in water, the effects attributed to fluid around hull must be taken into account. Therefore, vertical flexible modes of the model were also simulated by finite element method (FEM) in wet condition. The measured and simulated wet natural frequencies are summarized in Table 2. A good agreement between the prediction and experiment was found for the first-order vertical bending mode.

\section{Testing Results and Analyses}

3.1. Testing Schemes. The tests were conducted in the towing tank of Harbin Engineering University. The tank size is

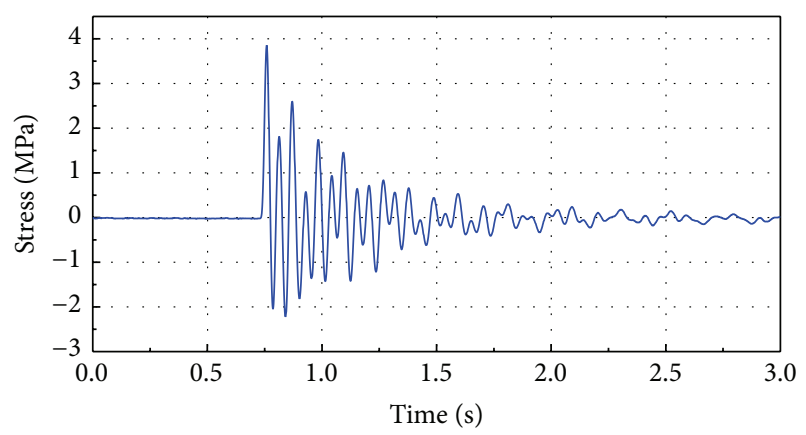

FIgURE 6: Hammering test in wet condition.

TABLE 3: Testing schemes.

\begin{tabular}{lccccc}
\hline Scheme & \multicolumn{2}{c}{ Speed } & \multicolumn{2}{c}{ Wave height } \\
& $\begin{array}{c}\text { Prototype } \\
(\mathrm{knot})\end{array}$ & $\begin{array}{c}\text { Model } \\
(\mathrm{m} / \mathrm{s})\end{array}$ & $\begin{array}{c}\text { Prototype } \\
(\mathrm{m})\end{array}$ & $\begin{array}{c}\text { Model } \\
(\mathrm{cm})\end{array}$ & $\lambda / L$ \\
\hline 1 & 21 & 1.528 & 12 & 24 & 1.0 \\
2 & 5 & 0.364 & 12 & 24 & $0.8 \sim 1.2$ \\
3 & 18 & 1.309 & 12 & 24 & $0.8 \sim 1.2$ \\
4 & 18 & 1.309 & $4 \sim 14$ & $8 \sim 28$ & 1.0 \\
5 & $0 \sim 24$ & $0 \sim 1.746$ & 12 & 24 & 1.0 \\
\hline
\end{tabular}

$108 \mathrm{~m}$ long, $7 \mathrm{~m}$ wide, and $3.5 \mathrm{~m}$ deep. Waves were made by a hydraulically driven wave maker of the single flap type, which generates regular and irregular waves. The model movements were measured by five-degree-of-freedom seaworthiness instrument.

The tests for wave loads correspond to three different control strategies, that is, constant sailing speed, constant wave height, and constant ratio of wave length $(\lambda)$ to ship length $(L)$. This paper presents the most critical test cases with different wave conditions and sailing speeds to investigate the nonlinear wave loads considering hull vibration and wave impact. The representative testing schemes selected in this paper are shown in Table 3.

\subsection{Analysis of Testing Results}

3.2.1. Load Components. The time histories of vertical bending moment (VBM) at different transverse sections of the model for corresponding sea state of scheme 1 are reported in Figure 7. In this figure the VBM time histories for 2nd, 4th, 6th, 8th, 10th, and 12th divisions are displayed in this order from top to bottom. The result was converted into the VBM of the real ship by use of the similitude rule. The measured VBM contains some high-frequency components, which is caused by transient vibration of the model hull due to bow slamming. For the sake of completeness, low-frequency (LF) load caused by waves and high-frequency (HF) load caused by bow impact were separated by use of Fourier filter and are presented in each graph.

Since the measured load is comprised of LF wave load and HF slamming load, the components of loads at different 

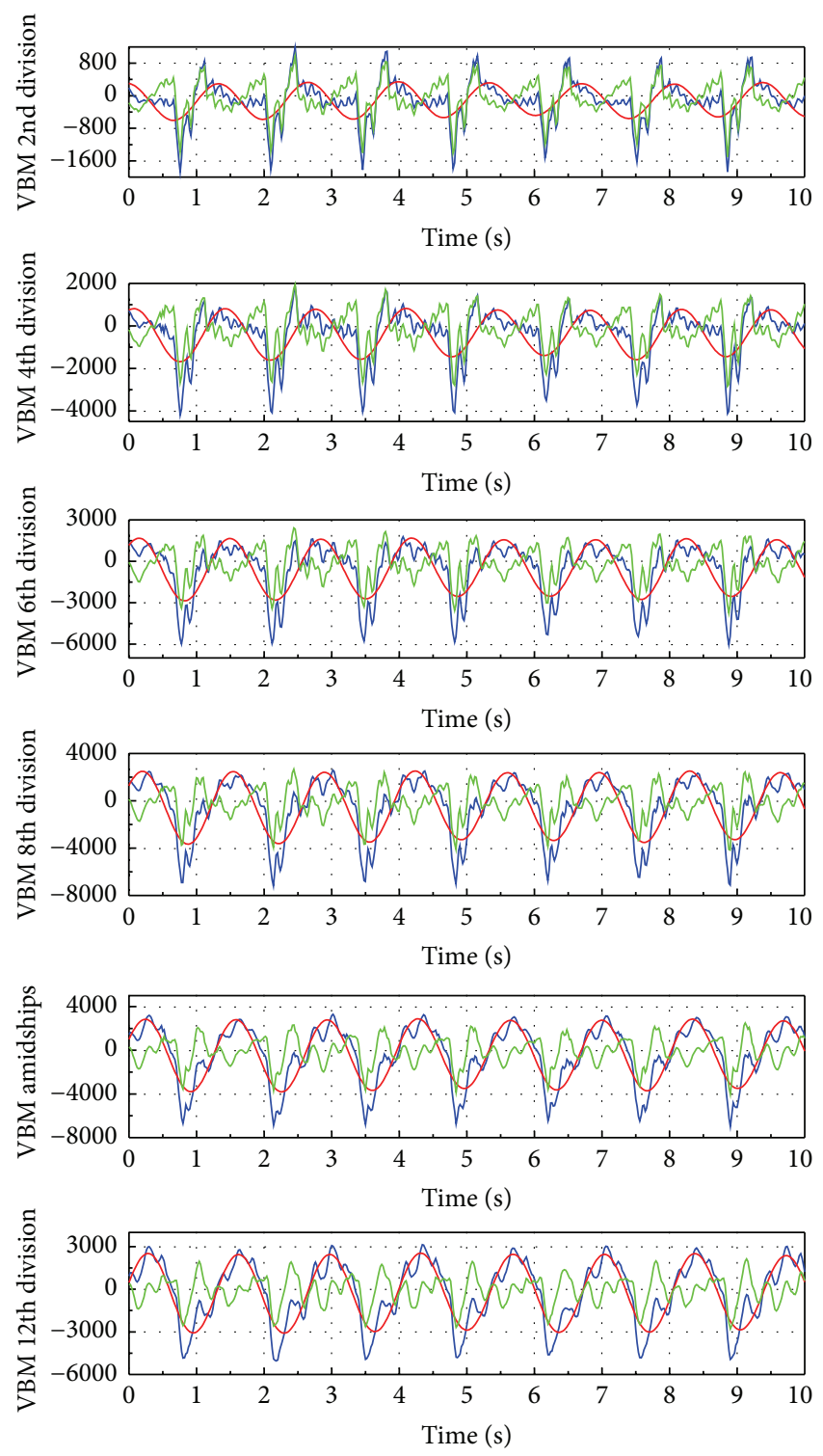

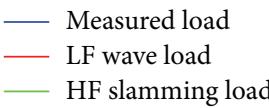

Figure 7: Time histories of VBM components at different divisions (scheme 1).

divisions along the ship are summarized in Figure 8. In addition, the ratios of LF load and HF slamming load to combined load at different divisions were calculated and shown in Figure 9.

It can be seen from the above analysis that the maximum combined load occurs at 10th division, which is amidships division. This VBM distribution rule was in fact similar for all the schemes mentioned above, and it can be achieved by beam theory. The curves in Figure 8 show that slamming load is larger than wave load at sections before the 7 th division of the ship because of severe bow slamming in particular. There is a rise of slamming moment from $2050 \mathrm{MN} \cdot \mathrm{m}$ at $2 \mathrm{nd}$ division to $5812 \mathrm{MN} \cdot \mathrm{m}$ at 8 th division. However, the ratio of

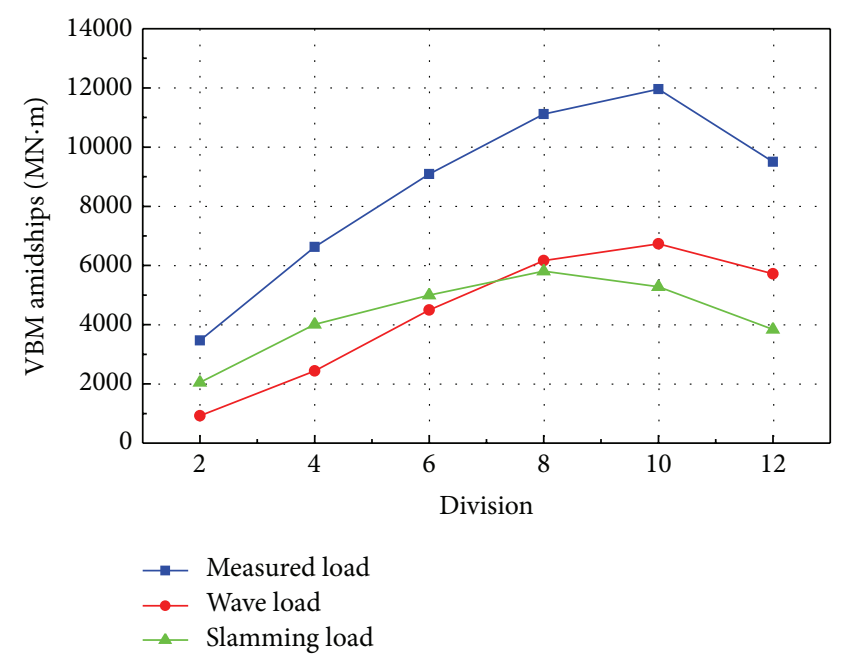

FIGURE 8: VBM components along ship (scheme 1).

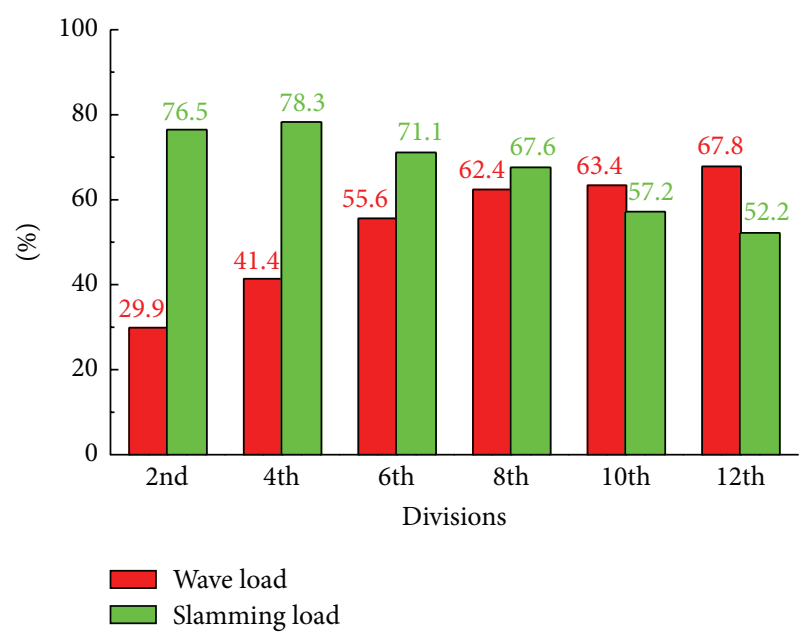

FIGURE 9: Ratios of components load to combined VBM load (scheme 1).

HF slamming load to combined load decreases from bow to stern, and the largest ratio, which is $78 \%$, occurs at 4 th division as shown in Figure 9.

3.2.2. Bow Impact Pressure. In addition, observation of severe bow slamming phenomenon can be made by video recordings. The following phenomena were observed during the tests: because of the ship's severe longitudinal motions, such as pitch and heave, violent bow flare impact occurs, as seen in Figure 10. The bow of the model emerged from the water, as shown in Figure 10(a), and then reentered the water at a relative high velocity, as shown in Figure 10(b).

The slamming pressures recorded by sensors arranged on bow of the model for corresponding condition of scheme 1 are listed in Table 4. The result was converted into the real ship's pressure by use of the similitude rule. Figure 11 shows the time history of slamming pressure at sensor number 1 as a representative sample. 


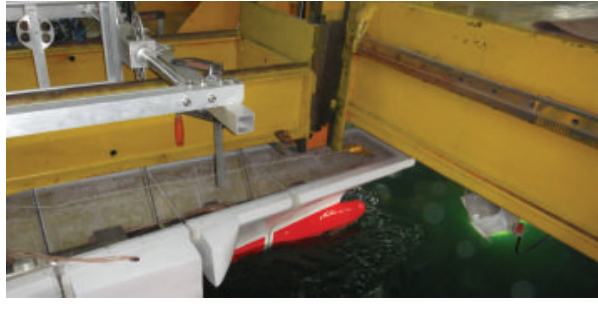

(a) Bow emerges from water

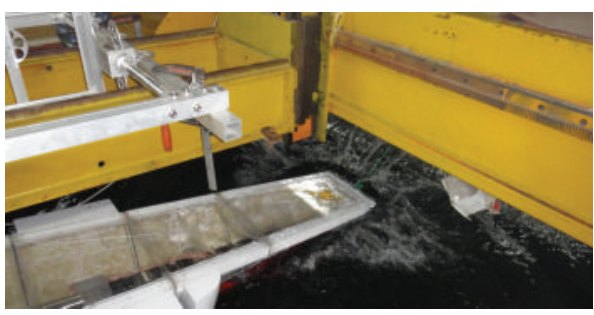

(b) Bow slamming

FIgURE 10: Bow impact with the wave (scheme 1).

TABLE 4: Impact pressure distribution (scheme 1).

\begin{tabular}{lc}
\hline Sensor number & Pressure/KPa \\
\hline 1 & 402 \\
2 & 708 \\
3 & 428 \\
4 & 703 \\
5 & 329 \\
6 & 231 \\
7 & 120 \\
8 & 203 \\
9 & 60 \\
10 & 90 \\
\hline
\end{tabular}

It can be seen from Table 4 that the maximum slamming pressure occurred at sensor number 2, which is located at centerline and near waterline (see Figure 3). From the values at sensors number 3 and number 4 at division $0.6 \#$ as well as sensors number 7 and number 8 at division 1.5\#, we can see that the impact pressure decreases dramatically at locations further up from the waterline. The reason for this is that the relative vertical velocity reduces after the bow impacts the water. Since the slamming pressure is proportional to the square of the relative vertical velocity, the pressure consequently reduces after the bow enters the water. The impact pressure beneath the waterline seems far more smaller than that above the waterline for sensors equidistant from the waterline. This can be seen from the values at sensors number 4 and number 5 at division $0.6 \#$ as well as sensors number 8 and number 9 at division 1.5\#. The flare slamming pressure at points located at same height from baseline decreases dramatically from forward perpendicular (FP) towards the amidships. This can be seen from the values at sensors number 2 , number 3 , number 7 , and number 10 as well as sensors number 4 and number 8 .

3.2.3. Vibration Harmonics. Slamming loads due to the linear, higher order wave excitations are investigated in regular waves. The frequency for occurrence of slamming phenomenon in regular waves could be calculated by the encounter frequency $[13,14]$ as follows:

$$
\omega_{e}=\omega\left(1-V \omega \cos \frac{\beta}{g}\right),
$$

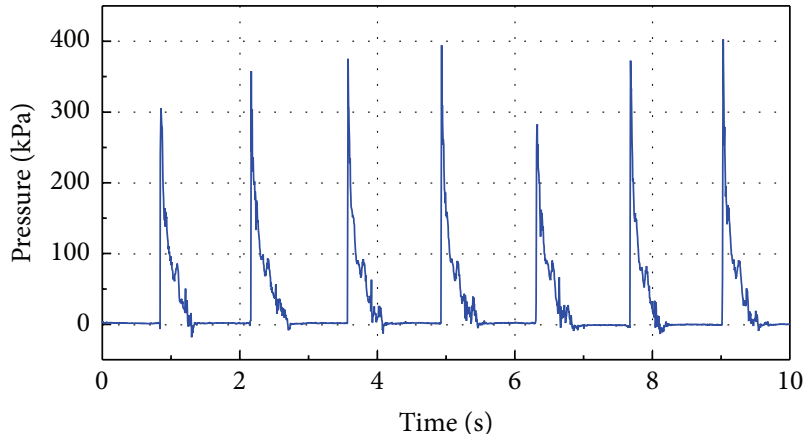

FIGURE 11: Time history of slamming pressure at sensor number 1 (scheme 1).

where $V$ is the sailing speed, $\omega$ is the wave natural frequency, and $\beta$ is the heading angle. In this scheme condition, $V$ is $1.528 \mathrm{~m} / \mathrm{s}, \omega$ is $0.507 \mathrm{~Hz}$ obtained from the wave length, and $\beta$ is $180^{\circ}$ for the head wave condition. The encounter frequency is $0.758 \mathrm{~Hz}$ by the formula above.

Because a ship oscillates with the wave encounter frequency, the exciting frequencies for hull vibration are the wave encounter frequency $\omega_{e}$ and its harmonics. The first and higher harmonic wave frequencies of encounter can be defined as follows:

$$
\omega_{e}^{(m)}=m \omega_{e}
$$

where $m$ is the $m$ th order harmonic encounter frequency.

In order to verify the above statement, spectral analysis method was adopted in processing the raw data of wave loads measured. The power spectral density (PSD) functions of the two time histories at 2nd and 10th divisions by FFT are shown in Figures 12(a) and 12(b), respectively. The first-order encounter frequency of the hull girder vibration is $0.735 \mathrm{~Hz}$ from the figure, with an error of $3 \%$ compared with the one calculated by (1).

As shown in Figure 12, there exist more HF components at 2 nd division compared with 10th division for the sake of bow slamming. This is consistent with the observations in Figures 7 9. The first 10 harmonic encounter frequencies appear at 2nd division and HF components account for a large proportion of energy. However, at 10th division there only exist the first 4 harmonic encounter frequencies, and LF components account for the largest proportion of energy. 


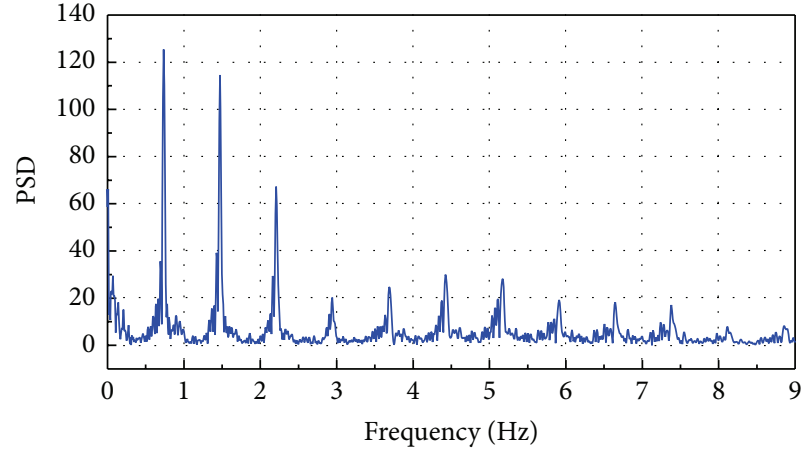

(a) PSD of 2nd division

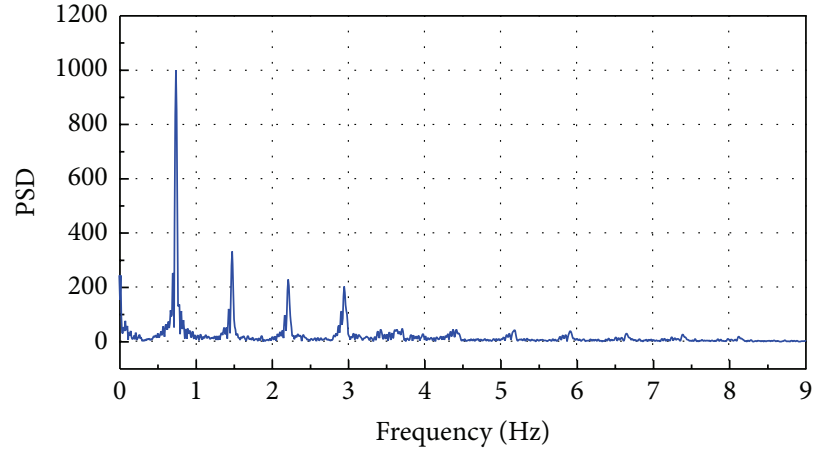

(b) PSD of 10th division

FIGURE 12: Power spectral density functions of VBM time histories (scheme 1).

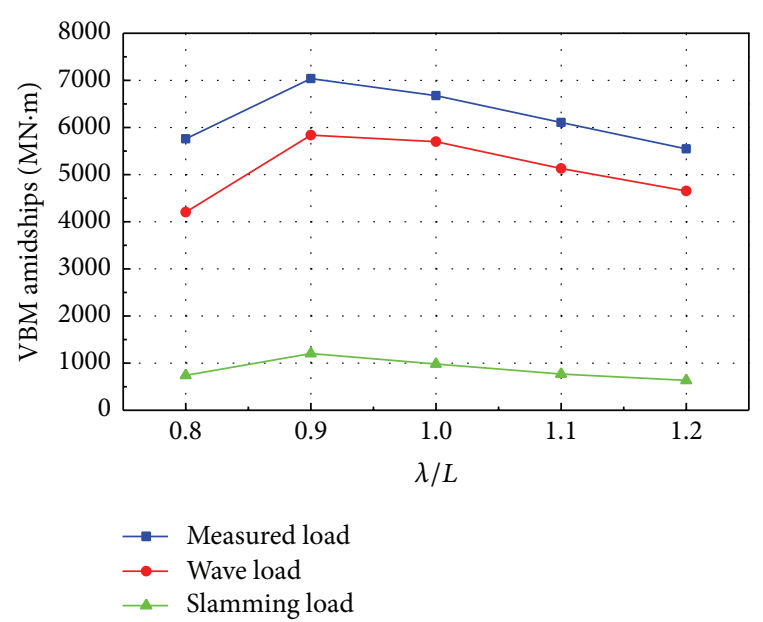

FIGURE 13: VBM amidships at different $\lambda / L$ of 5 knots (scheme 2).

3.2.4. Characteristics under Different Conditions. The hull vibrations and water impact have been studied by the condition corresponding to scheme 1 . To investigate the components under different seas or sailing speeds, the results of conditions for schemes 2 5 are analyzed below.

The test results of load components against wave frequency, that is, the wave length, for corresponding sailing speeds of 5 knots and 18 knots of schemes 2 and 3 are shown in Figures 13 and 14.

As the curves in the figures indicate, a considerable increase of HF slamming load occurs from 5 knots to 18 knots even at the same sea states. Both the curves in the two figures show the load response reaching the peak point at $\lambda / L$ of about 0.9 . This can be explained by the fact that the encounter frequency of this condition is closer to resonance frequency of the model hull.

The test results of load components against wave heights and sailing speeds, for corresponding schemes 4 and 5, are shown in Figures 15 and 16.

From the result in Figure 15, it can be seen that loads of each component increase with the increasing wave heights. It is clear that LF wave load is almost proportional to the wave height, which has already been confirmed by linear theory.

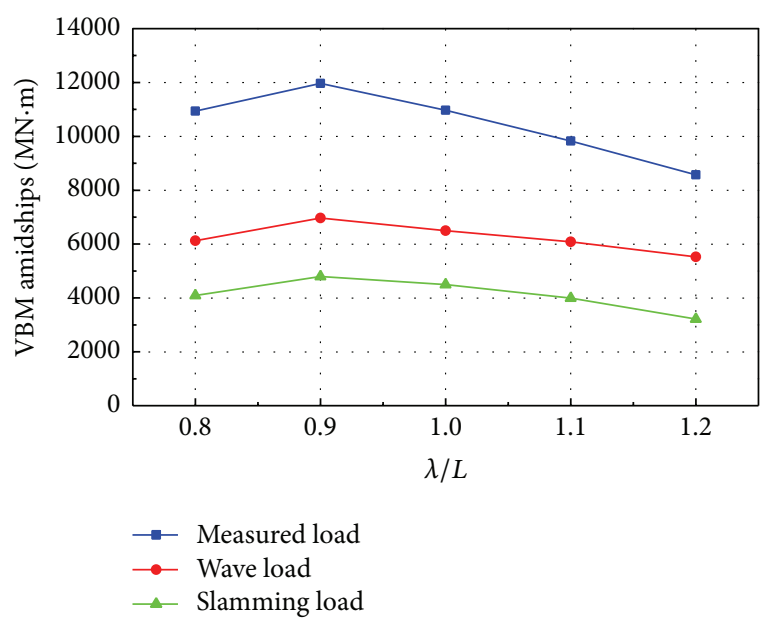

FIgURE 14: VBM amidships at different $\lambda / L$ of 18 knots (scheme 3 ).

However, as wave height increased, HF slamming load, unlike the LF load, increased dramatically due to nonlinear effects, which cause the combined load to increase nonlinearly. HF slamming load accounts for smaller component, which is $9 \%$, compared with LF wave load at wave height less than $6 \mathrm{~m}$; however it accounts for $43 \%$ in combined load at the wave height of $14 \mathrm{~m}$. The reason for this is that violent slamming phenomenon occurs in severe seas due to bow impact.

As shown in Figure 16, the curves of VBM components amidships at different sailing speeds are similar to those in Figure 15. Both of LF wave load and HF slamming load showed a general trend of increasing with the increasing sailing speed. LF wave load increased gradually with speed increase. Even as sailing speed increases from 0 knot to 24 knots, the LF wave load increases by only $33 \%$. HF slamming load accounts for smaller component compared with LF wave load at speed less than 5 knots but it is almost equal to LF wave load at 24 knots.

\section{Numerical Simulation}

4.1. Nonlinear Hydroelasticity Theory. Since the hull is a flexible body, traditional rigid theory cannot accurately reflect 


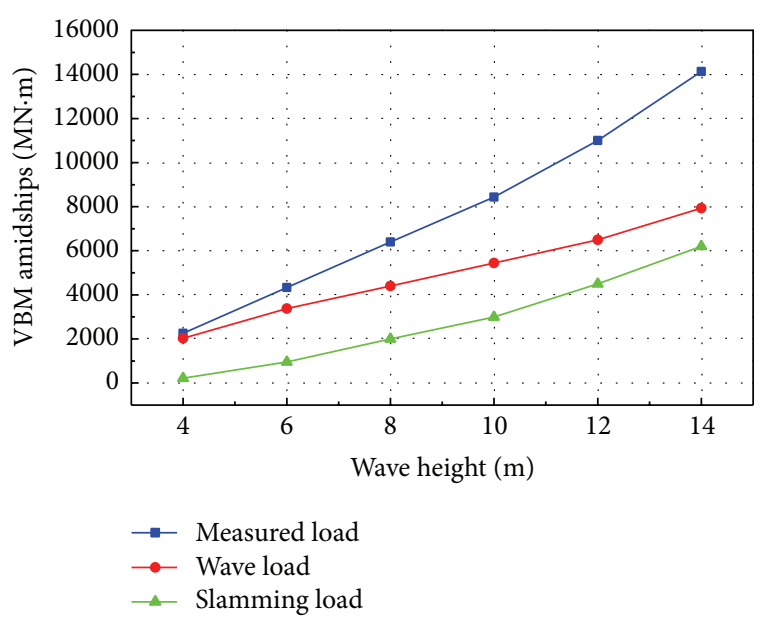

FIGURE 15: VBM components amidships at different wave heights (scheme 4).

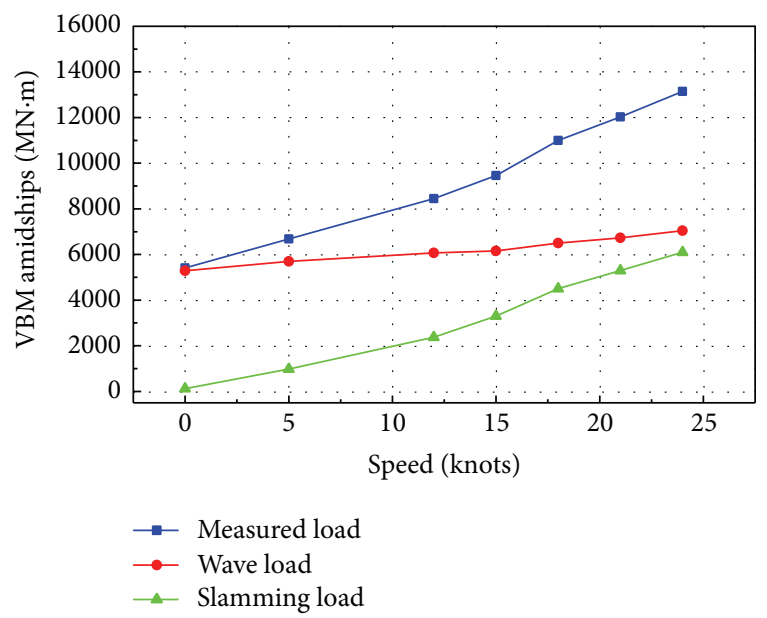

FIGURE 16: VBM components amidships at different sailing speeds (scheme 5).

the hull response to the high-frequency wave loads. Therefore, in order to calculate wave loads accurately, time domain hydroelasticity theory is adopted in this paper to simulate wave loads acting on the large ship in regular waves [15].

The motion equation of the structure, including both rigid displacement and distortion, in regular waves in time domain can be expressed as

$$
\begin{aligned}
([a]+[A]) & \ddot{p}_{r}(t)+([b]+[B]) \dot{p}_{r}(t) \\
& +([c]+[C]) p_{r}(t)=F_{I}(t)+F_{D}(t)+F_{\text {slam }}(t),
\end{aligned}
$$

where $[a],[b]$, and $[c]$ are generalized structural mass, damping coefficient, and stiffness matrices, respectively; $[A]$, $[B]$, and $[C]$ are generalized fluid added mass, damping coefficient, and stiffness matrices, respectively; $P_{r}(t)$ is the $r$ th mode principal coordinates amplitude vector; $F_{I}(t)$ is incident wave force; $F_{D}(t)$ is dispersion wave force; $F_{\text {slam }}(t)$ is slamming force.
The iterative calculation of the ship's motion and load responses in waves is done all the while when the ship moves around the mean position. Since the position of the ship relative to the wave changes all the time, the component forces are calculated on the instantaneous wetted surface meshes of the hull by the time domain method. Bow slamming and green water on the deck, which are caused by large amplitude motions, are also taken into account in the time domain simulation. The incident wave force acting on the instantaneous wetted surface of hull can be written as follows:

$$
F_{I}(t)=-\rho \zeta_{a} \iint_{S(t)} \vec{n} \cdot \vec{u}_{r}\left(i \omega-U \frac{\partial}{\partial x}\right) \phi_{0} d s
$$

Diffraction force on the instantaneous wetted body surface can be given as

$$
F_{D}(t)=-\rho \zeta_{a} \iint_{S(t)} \vec{n} \cdot \vec{u}_{r}\left(i \omega-U \frac{\partial}{\partial x}\right) \phi_{d} d s .
$$

Radiation force on the instantaneous wetted body surface can be given as

$$
\left\{F_{R}(t)\right\}=-\left[A_{r k}(t)\right]\left\{\ddot{p}_{r}(t)\right\}-\left[B_{r k}(t)\right]\left\{\dot{p}_{r}(t)\right\} .
$$

With added mass and damping coefficient expressed as follows:

$$
\begin{aligned}
A_{r k} & =\frac{-\rho}{\omega^{2}} \operatorname{Re} \iint_{S_{0}} \vec{n} \cdot \vec{u}_{r}\left(i \omega-U \frac{\partial}{\partial x}\right) \phi_{k} d s, \\
B_{r k} & =\frac{\rho}{\omega} \operatorname{Im} \iint_{S_{S_{0}}} \vec{n} \cdot \vec{u}_{r}\left(i \omega-U \frac{\partial}{\partial x}\right) \phi_{k} d s .
\end{aligned}
$$

Wagner model and momentum impact theory are the classical methods used to solve the slamming event in the time domain simulation. In this study, momentum impact theory is adopted to calculate the bow flare impact pressures. It is considered that the slamming force depends on the momentum change rate of the fluid around the bow. Slamming force could be obtained by using the following equation:

$$
F_{\text {slam }}(x, t)=\frac{d}{d t}\left[m_{\infty}(x, t) \frac{d}{d t} w_{\text {rel }}(x, t)\right]
$$

where $m_{\infty}(x, t)$ is the instantaneous added mass and $w_{\text {rel }}(x, t)$ is vertical displacement of the hull relative to the wave.

Fourth-order Runge-Kutta method is used to solve the equation. Since the waves are regular and the forward speed is constant, ship motions and loads experienced are repetitive cycles of the same form with a period same as the wave encountered period. Linear modal superposition method is used to calculate the loads. The first nine orders of the modal terms are taken into account in the superposition. The high order terms, which are ignored in the superposition, have little influence on the results. By substituting (4) (8) into (3) and taking an integral on the instantaneous wetted body surface, the displacement, moment, and shearing force of 

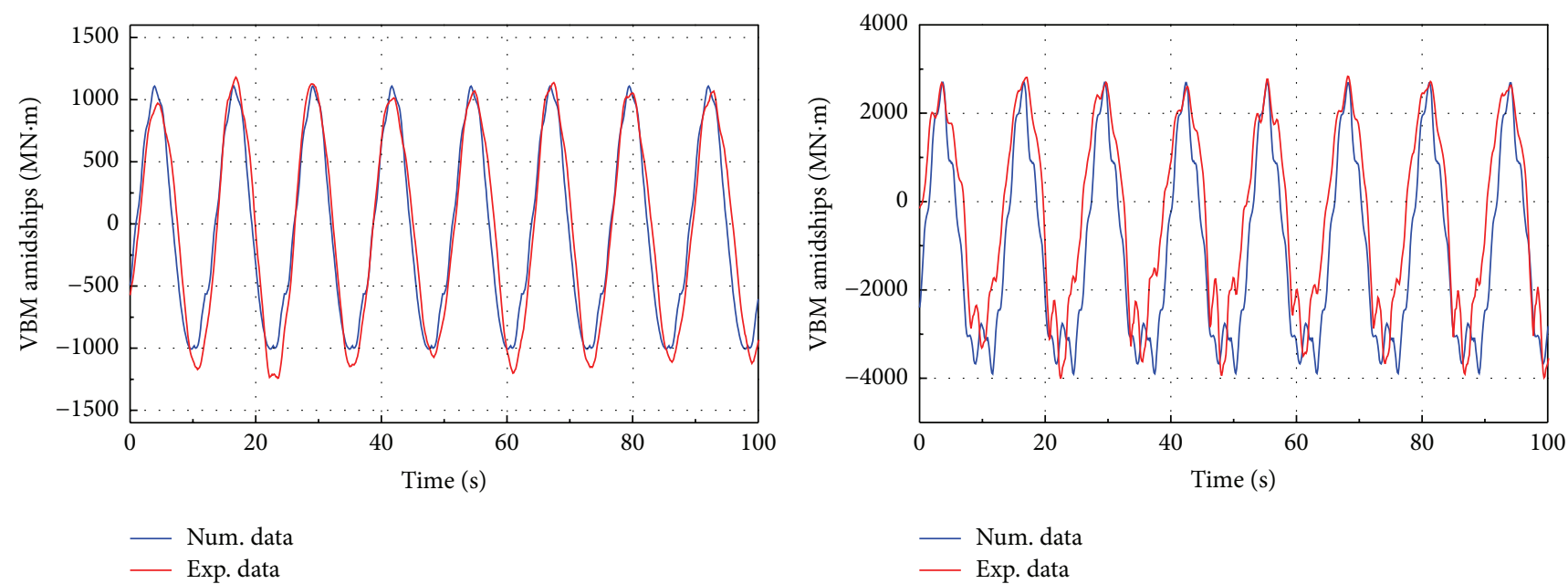

(a) $V=5$ knots; $H=4 \mathrm{~m}$

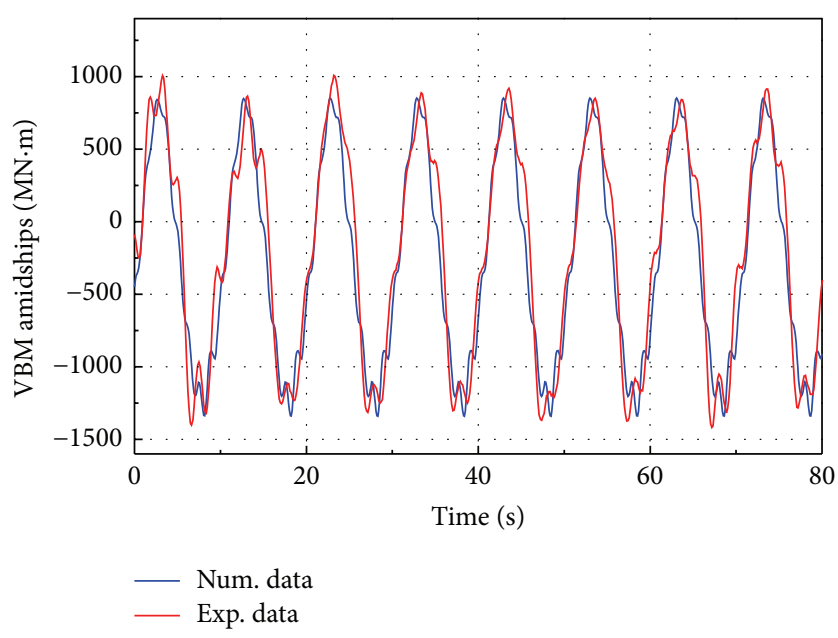

(c) $V=18$ knots; $H=4 \mathrm{~m}$

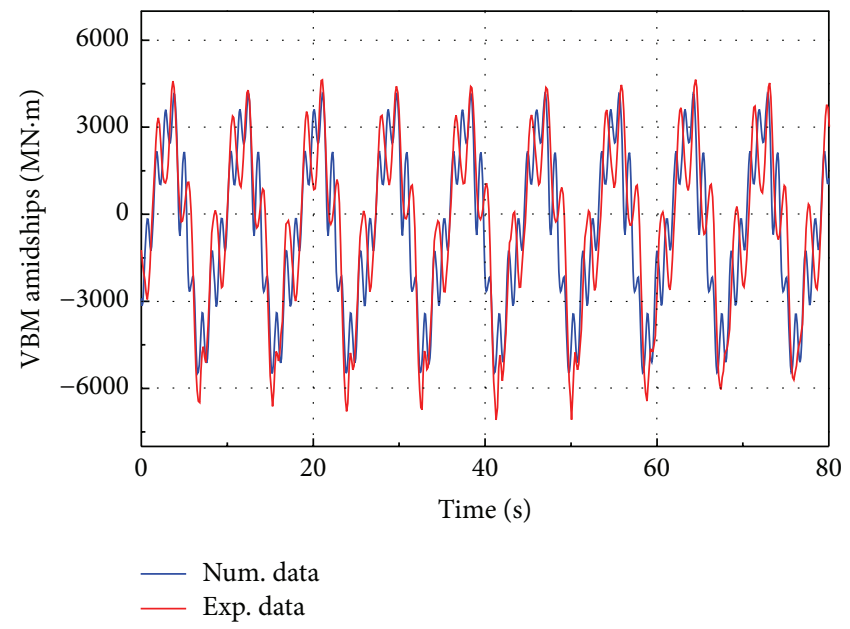

(d) $V=18$ knots; $H=12 \mathrm{~m}$

Figure 17: Comparison of the results.

a given cross section could be obtained by modal superposition method as follows:

$$
\begin{aligned}
w(x, t) & =\sum_{r=1}^{m} p_{r}(t) w_{r}(x), \\
M(x, t) & =\sum_{r=1}^{m} p_{r}(t) M_{r}(x), \\
V(x, t) & =\sum_{r=1}^{m} p_{r}(t) V_{r}(x),
\end{aligned}
$$

where $w_{r}(x), M_{r}(x)$, and $V_{r}(x)$ are the $r$ th natural mode of the model's displacement, moment, and shearing force, respectively. While $r=1 \sim 6$ denotes the rigid body motion mode of six degrees of freedom, $r \geq 7$ denotes the deformation modes.

4.2. Comparison of the Results. Four typical conditions were selected for the comparison of the results. The time histories of the numerical as well as the experimental results are shown in Figure 17.

It is confirmed in the figure above that the numerical results show good agreement with the experimental ones. It is observed from Figure 17(a) that only slight slamming response has taken place at trough of the curves in low seas and low sailing speed. With increasing wave height or sailing speed, a considerable slamming load occurred at trough of the curves, as confirmed in Figures 17(b) and 17(c). This can be interpreted by the fact that while the wave through is at amidships and wave crest at the bow and stern, the hull is in a sagging bending condition so the VBM is negative value; meanwhile the crest of wave hits the bow flare which causes slamming load. The slamming load increased rapidly, as shown in Figure 17(d), with higher speed and higher wave height.

The combined loads are $2135 \mathrm{MN} \cdot \mathrm{m}$ and $6537 \mathrm{MN} \cdot \mathrm{m}$ corresponding to wave heights of $4 \mathrm{~m}$ and $12 \mathrm{~m}$, respectively, at the speed of 5 knots (see Figures 17(a) and 17(b)). It is clear that $\mathrm{VBM}$ are almost proportional to wave heights 
in these conditions because the nonlinear HF slamming loads are not pronounced. However, the loads increased from $2237 \mathrm{MN} \cdot \mathrm{m}$ to $9510 \mathrm{MN} \cdot \mathrm{m}$ when the wave heights increased from $4 \mathrm{~m}$ to $12 \mathrm{~m}$ (see Figures $17(\mathrm{c})$ and 17(d)). The unproportional increase is caused by severe slamming loads, which is consistent with the results in Figure 15.

\section{Conclusions}

In this paper, hull girder vibrations and wave impact response of a large ship in regular waves were studied by experimental and numerical methods. A scaled segmented model with steel backbone system to match the vibration characteristics of prototype ship was designed and tested in tank. The numerical simulations were also performed by using the threedimensional time domain nonlinear hydroelastic method to estimate the wave loads responses of the ship. From the experimental and numerical simulation results, the following conclusions can be made:

(1) Hydroelastic method is a better approach to solve the problems of fluid-structure interaction considering hull vibration and deformation compared with rigid theory.

(2) The high-frequency vibration loads of hull caused by slamming event and harmonic wave frequencies of encounter, which may even be larger than wave frequency loads, must be taken into consideration in design and operation of large ships.

(3) The HF response caused by slamming event is not pronounced at low seas with low sailing speed, and the wave load response can be well solved by linear rigid theory. However, elastic effects and HF vibration of the hull must be taken into consideration at high seas or high sailing speeds, or both.

(4) Coupled with elastic beam model, the nonlinear hydroelastic analysis considering slamming event and other nonlinear effects proved to be a very efficient and accurate method to simulate the wave loads of large ships in regular waves.

In this work, regular waves were considered in the investigation of hull girder vibrations and bow impact of the ship by experimental and numerical methods. In the future, we intend to carry out studies of hull girder vibrations and bow impact of the ship sailing in actual sea wave conditions, including both of long-crest and short-crest irregular wave conditions, by both experimental and numerical methods. More nonlinear factors will be considered to make the numerical simulation results more accurate.

\section{Conflict of Interests}

The authors declare that there is no conflict of interests regarding the publication of this paper.

\section{Acknowledgments}

This work was supported by the National Natural Science Foundations of China (no. 51079034 and no. 51209054). The authors would like to express their gratitude to these foundations.

\section{References}

[1] R. Miyake, T. Matsumoto, N. Yamamoto, and K. Toyoda, "On the estimation of hydroelastic response acting on a ultra-large container ship," in Proceedings of the 20th International Offshore and Polar Engineering Conference, vol. 4, pp. 849-856, June 2010.

[2] W. Cui, J. Yang, Y. Wu, and Y. Liu, Theory of Hydroelasticity and Its Application to Very Large Floating Structures, Shanghai Jiao Tong University, 2007.

[3] S. E. Hirdaris, W. Bai, D. Dessi et al., "Loads for use in the design of ships and offshore structures," Ocean Engineering, vol. 78, pp. 131-174, 2014.

[4] R. E. D. Bishop and W. G. Price, Hydroelasticity of Ships, Cambridge University Press, 1979.

[5] I. Senjanović, Š. Malenica, and S. Tomašević, "Investigation of ship hydroelasticity," Ocean Engineering, vol. 35, no. 5-6, pp. 523-535, 2008.

[6] F.-C. Chiu, W.-C. Tiao, and J. Guo, "Experimental study on the nonlinear pressure acting on a high-speed vessel in irregular waves," Journal of Marine Science and Technology, vol. 14, no. 2, pp. 228-239, 2009.

[7] L. Sebastiani, F. Valdenazzi, L. Grossi, and G. K. Kapsenberg, "Theoretical/experimental investigation of the slamming pressure on fast monohull vessels," in Proceedings of the 6th International Conference on Fast Sea Transportation, pp. 109116, Royal Institution of Naval Architects, Southampton, UK, 2001.

[8] G.-D. Xu and W.-Y. Duan, "Review of prediction techniques on hydrodynamic impact of ships," Journal of Marine Science and Application, vol. 8, no. 3, pp. 204-210, 2009.

[9] Z.-Y. Chen, H.-L. Ren, H. Li, and K.-H. Zhang, "Experimental and numerical analysis of bow slamming and whipping in different sea states," Journal of Ship Mechanics, vol. 16, no. 3, pp. 246-253, 2012.

[10] Z.-Y. Chen, H.-L. Ren, and H. Li, "Application of hydroelasticity theory and segmented model test in hull vibration response analysis," Journal of Vibration and Shock, vol. 31, no. 24, pp. 119124,2012

[11] H. Li, 3-D hydroelasticity analysis method for wave loads of ships [Ph.D. dissertation], Harbin Engineering University, 2009.

[12] H. Li, H.-L. Ren, R.-M. Liu, and G.-Q. Feng, "3-D hydroelastic method for analysis of motion and wave loads of an FPSO ship," Journal of Harbin Engineering University, vol. 29, no. 8, pp. 789793, 2008.

[13] S. P. Kim and H.-C. Yu, "Segmented model testing and numerical analysis of wave-induced extreme and springing loads on large container carriers," in Proceedings of the 20th International Offshore and Polar Engineering Conference, pp. 385-392, June 2010.

[14] Y. Lee, N. White, Z. Wang, S. E. Hirdaris, and S. Zhang, "Comparison of springing and whipping responses of model tests 
with predicted nonlinear hydroelastic analyses," in Proceedings of the 21st International Offshore and Polar Engineering Conference, pp. 453-460, 2011.

[15] S. E. Hirdaris and P. Temarel, "Hydroelasticity of ships: recent advances and future trends," Proceedings of the Institution of Mechanical Engineers Part M: Journal of Engineering for the Maritime Environment, vol. 223, no. 3, pp. 305-330, 2009. 

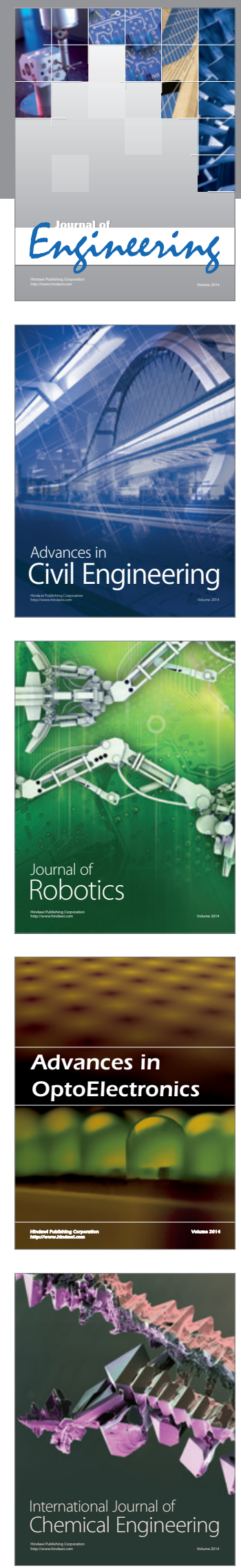

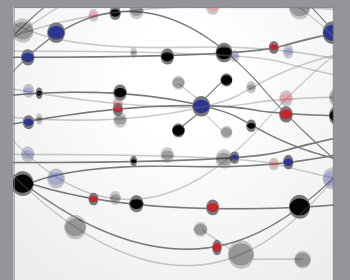

The Scientific World Journal
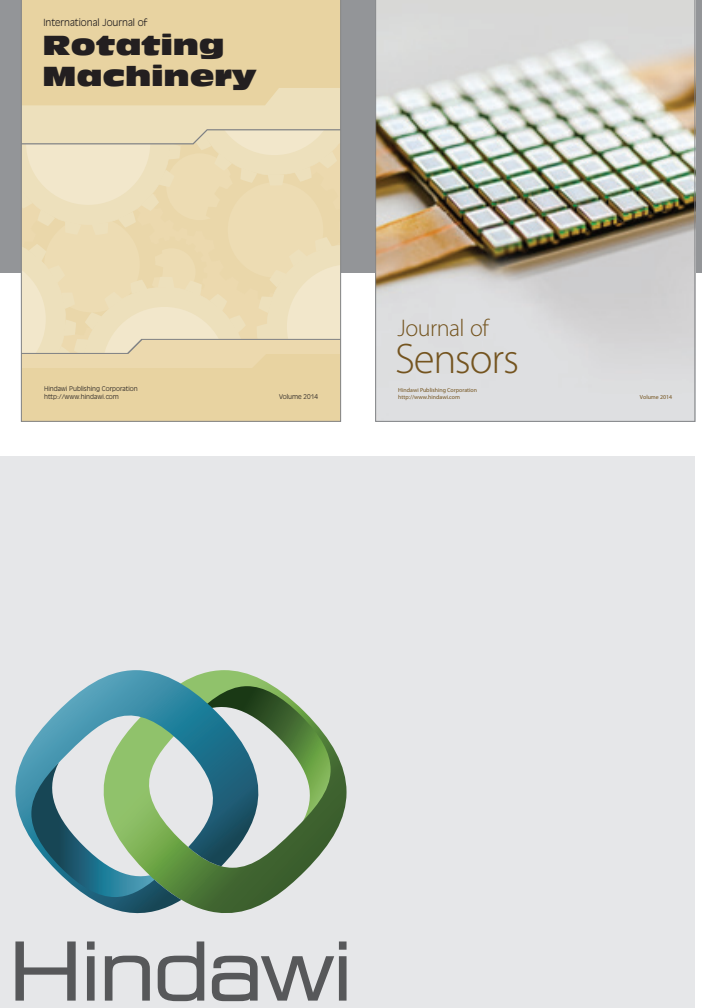

Submit your manuscripts at http://www.hindawi.com
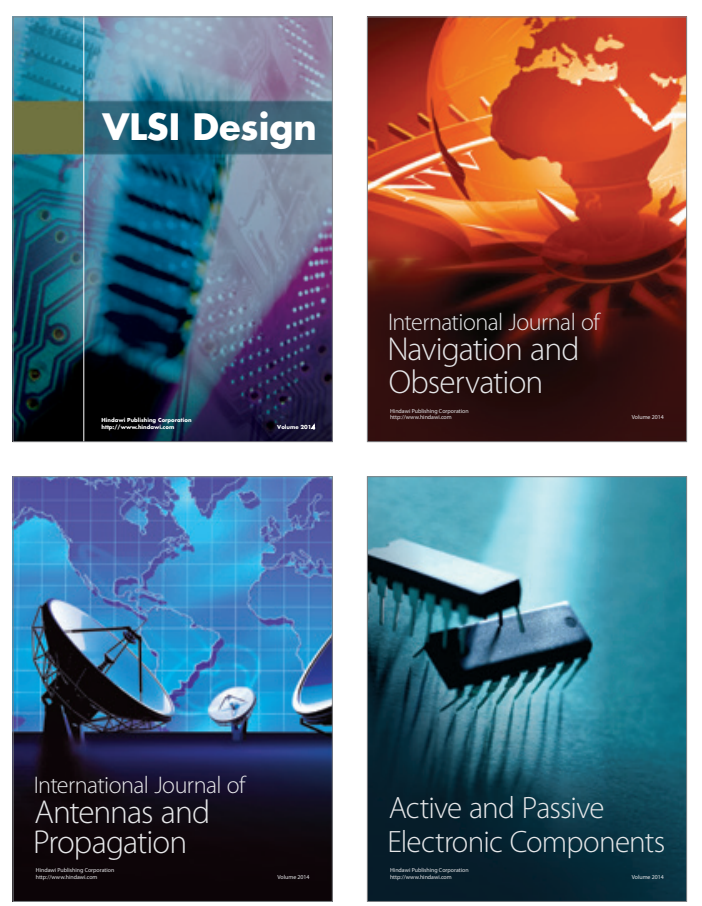
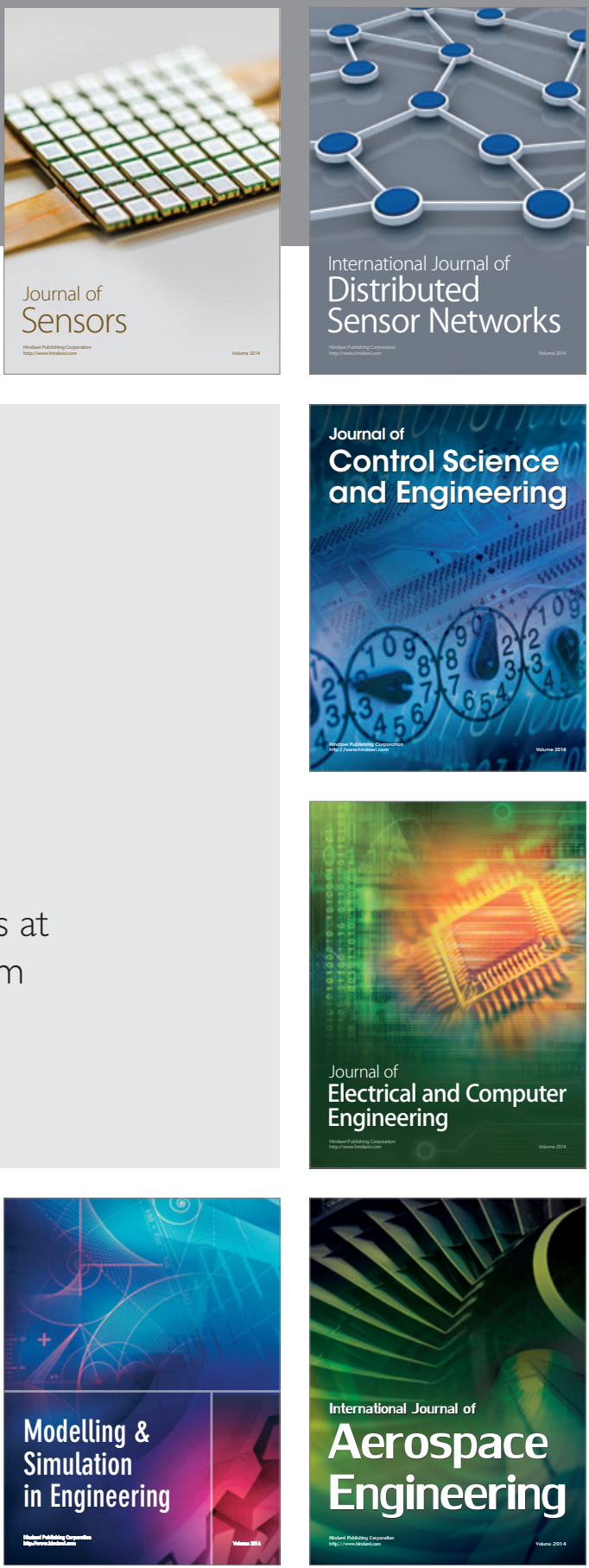

Journal of

Control Science

and Engineering
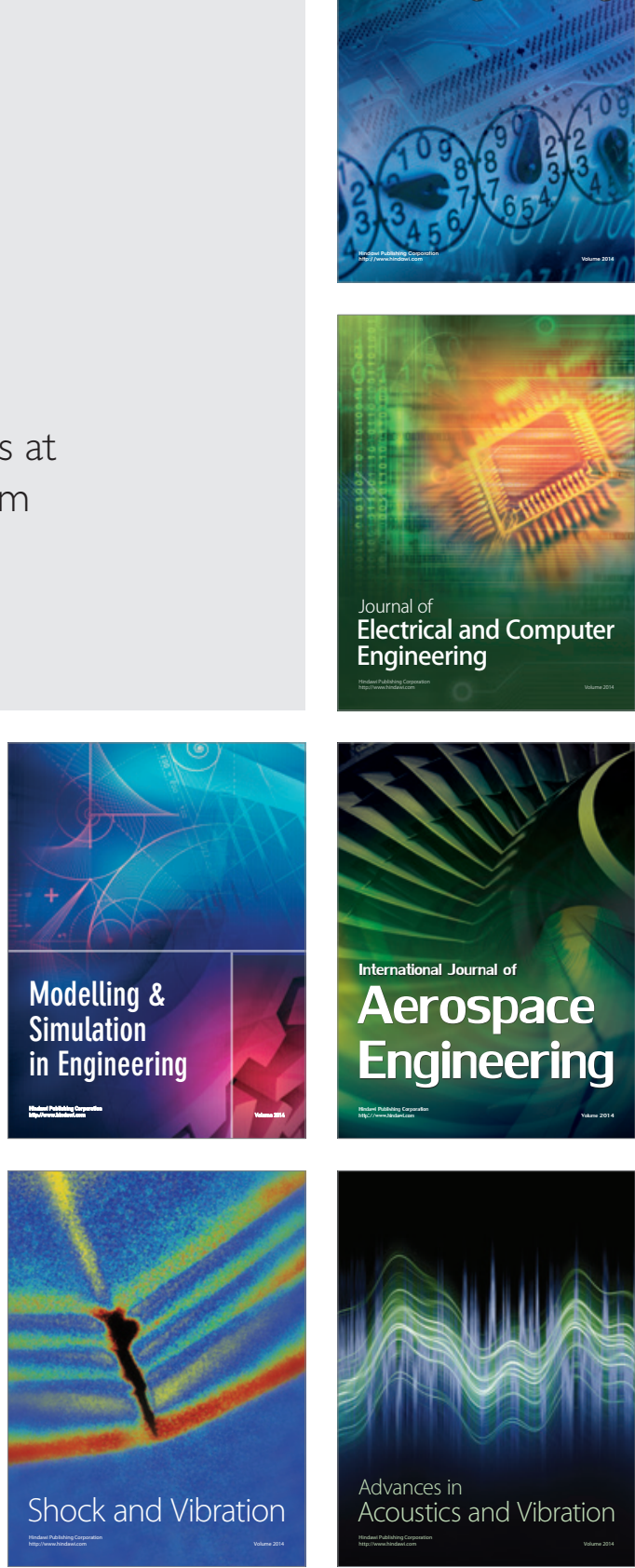